\title{
Assamese Verb Serialization in Functional, Areal-Typological and Diachronic Perspective*
}

\author{
MARK POST \\ Research Center for Linguistic Typology
}

\section{Introduction}

In Southeast Asian and West African linguistics, clauses containing multiple chained verbs are typically referred to as "serial verb constructions". In the South Asian linguistic tradition, the closest analogue to the serial verb construction is often labeled a "compound" or "explicator compound" verb (Brown 1997; Burton-Page 1957; Hacker 1961; Hook 1974; Kachru and Pandharipande 1980; Nespital 1989), to some a subtype of "converb" construction or "conjunctive participial" (Bisang 1995 and references therein). Qualified use of the term "serialization" has occasionally been introduced (Kachru 1979; Kachru 1993; Pandharipande 1993; Steever 1989). However, a detailed comparative study of multi-verb constructions in e.g. South and Southeast Asian languages remains to be conducted. ${ }^{1}$

While our data at present remain insufficient to conduct this larger study, I argue in this paper that verb chains in at least Assamese are in fact direct analogues to the serial verb constructions of West Africa and Southeast Asia. Structurally, their surface syntax is comparable in the crucial respects, and they exhibit analogous properties with respect to argument structure, scope of tenseaspect marking and polarity. More tellingly, however, they share a precisely analogous diachronic origin and functional motivation for their development, as well as serve as a primary channel for the recruitment of new grammatical morphemes. Although in terms of frequency distribution, as well as sheer number of functions handled, verb-serialization appears far deeper in more prototypical

\footnotetext{
* This work is based on research initially conducted at the University of Oregon. Data in this paper were elicited by the author from native speaker consultants except where cited and/or marked by a text reference of the form XX:\#. I thank my Assamese consultants, Tanusri Borgohain and Priyanka Roy, my Thai consultant Duangkamol Sutthiwari, my Chinese consultant Kun Yue, and my Japanese consultant Naomi Hasebe. Eric Pederson commented helpfully on an earlier version of this work; all errors remain mine.

${ }^{1}$ A good introduction to the more general problem of the relationship between converbs and serial verbs may be found in Bisang (1995).
} 
verb-serializing languages such as Lahu or Akan, these differences should probably be understood in terms of typological constraints on their development rather than as differences of kind per se.

The paper has the following structure: Section 1 briefly discusses some typological features of Assamese with reference to contact in the Northeast Indian linguistic area. Sections 2 and 3 review the synchronic and diachronic characteristics respectively of serial verb constructions in languages commonly identified as having them. Section 4 then reviews the major structural and semantic features of the Assamese serial verb construction. Section 5 concludes the presentation.

\section{Typology and the contact situation of Assamese}

As the Easternmost Indo-Aryan language, situated in the sub-Himalayan Brahmaputra plain, Assamese has enjoyed prolonged contact with Southeast Asian languages of Tai, Tibeto-Burman, and Mon-Khmer stock (Kakati 1995). An important regional lingua franca, Assamese has been creolized at least once on a large scale by southern Nagas and Bodo-Kacharis (Bhattacharjya 2001). Perhaps unsurprisingly given these available influences, Assamese has shed some stereotypically Indic traits. The modern language lacks retroflex stops and continuants, has lost verbal cross-referencing of gender and number, and has a relatively reduced and highly pragmatically-sensitive set of case-forms (Edwards 2004; Goswami and Tamuli 2003). At the same time, it has gained young but evidently robust systems of numeral classifiers and relator nouns (Benom MS), and can in general be said to have shifted towards a relatively more isolating morphological profile than its ancestors and Indic neighbors. ${ }^{2}$ At the same time, the perseverance of at least some morphological markers of tense-aspect and argument crossreferencing on the verb, as well as an overall tendency towards polysyllabism, sets Assamese clearly apart from the monosyllabic, extreme isolating languages of Southeast Asia, in which verb-serializations are found par excellence. These typological facts may be kept in mind as the constructions I will analyze as verb serializations in these different types of languages are compared. ${ }^{3}$

\section{Verb serialization - synchrony}

"Verb-serialization" is widely understood in the sense(s) developed through the study of West African languages on the one hand (Givón 1975; Lord 1993, and

\footnotetext{
${ }^{2}$ There are even some reports of tonogenesis in consort with the simplification of rhymes in certain western dialects of Assamese (Stephen Morey, p.c.), however the subject remains to be fully investigated.

${ }^{3}$ Transcriptions: Assamese data are given in a practical orthography, following IPA except where $\left.O=[\mathrm{o}], r=[\mathrm{I}], z=[3], h={ }^{\mathrm{h}}\right] / \mathrm{T}_{-}$and [G] $/ \mathrm{D}_{-}$, \#_; since my transcriptions reflect the actual speech of my consultants, who are each of relatively diverse dialect backgrounds (but correspond in most details to Goswami and Tamuli's (2003) "Western Assamese"), they may differ somewhat from transcriptions found elsewhere in the literature. Thai data follows Haas (1964), with the exception that Haas' syllable-final voiced stops are transcribed here as voiceless. Japanese data follow IPA except where $s h=[c]$. Chinese data are in pinyin. All other data follow the transcription system used by the author of the work cited.
} 
many others; Sebba 1987) and Southeast Asian languages on the other (Li and Thompson 1973; Schiller 1990, and many others). Representative examples from Akan and Thai are given in (1-2).

mi a fa sekan e twa

Akan

1 PF take knife PF cut

'I have cut with a knife.'

(Akan data from Byrne (1990))

(2) phǒm dâj Paw mîit paj hàn

Thai

1 can take knife go cut

'I was/am able to go cut with a/the knife.'

All of the terms glossed above in bold are capable of standing alone as the single verb of a simplex predicate, with the semantic values given. No overt marking confers a special status on any individual or subset of the verbs, i.e. as subordinated to or coordinate with a main verb, and they share the same subject, same TAM specification, and the same polarity; these are all strong tendencies of serial verb constructions cross-linguistically. Verb serializations also tend strongly to code a single event, or a tightly-bound sequence of temporally or analytically distinct events (often entailing causality or result), and are frequently found to fall under the same intonation contour. A concise review of these prototypical characteristics of serial verb constructions may be found in Seuren (1990).

Difficulties emerge due to the fact that certain verbs in a series will tend to exhibit more or less lexical characteristics, forming the semantic core of the predicate (e.g. 'cut' in 1-2 above), while others exhibit more or less functional properties, and appear to modify the semantic core with aspectual, directional or some other type of information. Disagreements have accordingly developed in synchronic analysis of the categorical status of serialized verbs, on the one hand, and the underlying structure of the clause in which they appear, on the other. However, taken from a diachronic perspective, the salient properties of serial verb constructions as well as their utility as a primary channel for the recruitment of new grammatical structures have a ready interpretation; the problem of categorical intermediacy can be accordingly re-cast as a problem of extent or degree of grammaticalization.

\section{Serial verb constructions - diachrony}

As demonstrated by Givón (1991; 1995), serial verb constructions arise diachronically through clause-integration. This is a functionally well-motivated operation maximizing efficiency in presentation when consequent clauses share much in common, e.g. subject, TAM and polarity. Speakers can omit overt reference of common elements, and, particularly in isolating and/or primarily dependent- 
marking languages without much finite verb morphology, place two verb phrases under the same intonation contour.

From this point, integration of relatively unmarked lexemes under the same intonation contour creates prosodic and adjacency conditions which are ideal to grammaticalization; and, as may be expected, frequently-occurring and semantically general serial verbs are invariably recruited by verb-serializing languages as markers of aspect, modality and noun case, in addition to performing innumerable types of adverbial modification. Detailed, diachronically-informed case studies are widely available in the literature ( $\mathrm{Li}$ and Thompson 1974; Lord 1993; Matisoff 1991; Post 2003, and others; Sun and Givón 1985).

To summarize this perspective (schematized in Figure 1): over time we find a relatively less well-formally-integrated clause chain coding temporally or analytically distinct events becomes gradually more well-formally-integrated as a verb chain, i.e. a serial verb construction. ${ }^{4}$ The more compact construction that results is accordingly available to interpretation as a single event; in the extreme case, one or more of the verbs is semantically bleached and may be found performing some grammatical function.

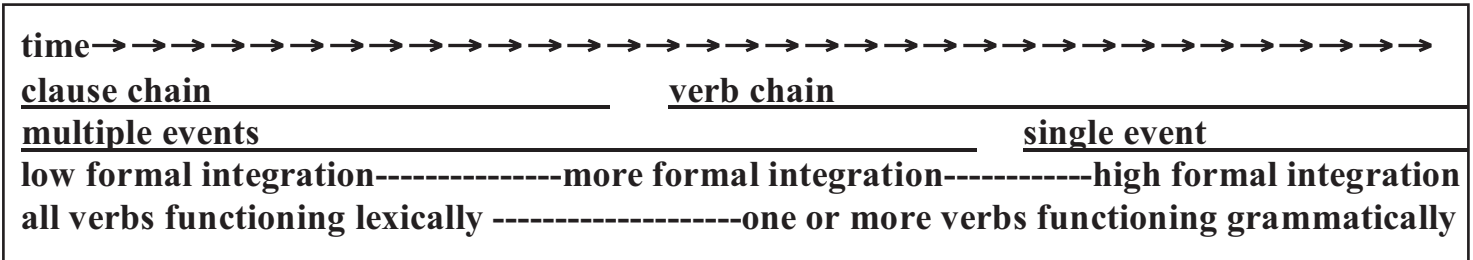

Fig. 1 - Rise of verb serializations from clause chains

With this scenario in mind, we'll turn now to the so-called (explicator) compound verb construction in Assamese, and see that it may be similarly characterized, from both a synchronic and a diachronic perspective.

\section{Verb Serialization in Assamese}

The immediate source of the Assamese serial verb construction is a conjunctive participial construction, found widely in the SOV languages of South, Central and East Asia. As shown in example (3) from Marathi, an Indo-Aryan language spoken in and around Bombay, and in (4) from Japanese, we find a suffixed participial form of an initial or medial verb, followed by a finite final verb, giving us events in a temporal sequence.

$$
\begin{aligned}
& \text { Madhū he bol-ūn ghar -ì ge-lā } \\
& \text { Madhu this say-CONJ house-LOC go-PST.3.SG.M } \\
& \text { 'Having said this, Madhu went home.' } \\
& \text { (data from Pandharipande (1993), adjusted MP) }
\end{aligned}
$$

\footnotetext{
${ }^{4}$ I use the term "clause chain" here roughly in the sense of DeLancey (1991).
} 


$$
\begin{aligned}
& \text { watashi-wa yut-te ie }- \text { ni kaet -ta } \\
& 1 \text {-TOP say-CONJ house-LOC return-PFV } \\
& \text { 'I spoke and went home.' }
\end{aligned}
$$

Likewise in Assamese, when two semantically particular verbs occur in this construction, the resulting interpretation is a pair of events in temporal sequence (5). However, as shown in (6), when a more semantically general verb finishes the construction, the resulting interpretation is often not of an event sequence, but rather a single event. In this case, the first verb "write" forms the semantic core of the predication, and the second verb modifies it aspectually.

$$
\begin{aligned}
& m O i \quad l i k h-i \quad k h a-l \quad-u \\
& \text { 1.NOM write-NF eat -PST-1.SUB } \\
& \text { 'I wrote (and then) ate.' }
\end{aligned}
$$

Assamese

$$
\begin{aligned}
& m O i \quad \text { likh }-i \quad \text { as } \quad-i l \quad-u \\
& \text { 1.NOM write-NF have/exist-PST-1.SUB } \\
& \text { 'I was writing.' }
\end{aligned}
$$

Assamese

Thus, while the verbal suffix $-i$ seems clearly to derive from a conjunctive suffix alike to those found in e.g. Marathi and Japanese, its functional load in Assamese remains subject to question. Unlike in many so-called 'clause-chaining' languages, Assamese has an independent marker of conjunction aru 'and', which is often used in consort with a conjunctive participial form. In any case, whether or not the $-i$ suffix is functioning to conjoin two predicates in (5), it clearly no longer has this function in a sentence like (6). I therefore gloss it here as a non-finite marker. ${ }^{5}$

\section{1. $\quad$ Structure}

The first condition of verb serialization is certainly that more than one verb be involved, and, perhaps, the more the better. In deep serializing languages like Thai or Lahu, it is by no means uncommon to find sequences of four to six verbs or more in a single clause (Matisoff 1969). Although comparative statistics are not yet available, it appears that the vast majority of Assamese serializations involve only two or three verbs; more extended chains may be elicited, but in texts chains greater than three verbs typically occur only as the result of stereotyped reduplications, as in (7).

\footnotetext{
5 There are other reasons for believing the $-i$ suffix is no longer analyzed by speakers as a conjunction per se - for example, all tense-aspect suffixes in Assamese carry an initial $i$ (deleted when following vowel-final stems), viz. Perfect -is, Past -il, Subjunctive and Third person future $i b O$, and First person future $-i m$. It is possible that the $-i$ suffix was long ago generalized as a predicate marker.
} 
ta-i ula $-i$ dza-i ula $-i \quad$ go $-i$ pela $-i$ bhab-e... 3 -F emerge-NF go ${ }^{\mathbf{a}}$-NF emerge-NF go $^{\mathbf{b}}$-NF throw-NF think-3.SUB 'She goes ahead on out and thinks...'

(Data from Joana Jansen, BP:4; gloss adjusted MP)

\subsubsection{Argument structure}

As already noted, serial verb constructions cross-linguistically tend to take a single subject. ${ }^{6}$ True conjunctive participial constructions tend to be somewhat looser; for example, in Japanese, either a different (8) or a same subject (9) may intervene between the conjoined predicates.

$$
\begin{aligned}
& \text { watashi-ga kai -te kare-ga tabe-ta } \\
& \mathbf{1}-\text {-SUB write-CONJ 3.M -SUB eat -PFV } \\
& \text { 'I wrote (it) and he ate (it).' }
\end{aligned}
$$

$$
\begin{aligned}
& \text { watashi-ga kai-te (watashi-ga) tabe-ta } \\
& \text { 'I wrote it and (I) ate it.' }
\end{aligned}
$$

Japanese

By contrast, in Assamese, intervention of different (10) or same subjects (11) is rejected by my consultants, who prefer to coordinate two finite clauses instead (not shown).

$$
\begin{aligned}
& \text { * mOi likh }-i \quad \text { (xi) kha }-l \text {-e Assamese } \\
& \text { 1.NOM write -NF (3.M.NOM) eat -PST-3.SUB }
\end{aligned}
$$

$\sim$ 'I wrote and I ate.' (even with stress on second $m O i$ )

However, as in the Thai example (2) above and in verb-serializing languages generally, serialized verbs in Assamese may take separate object or oblique arguments which may then interrupt the chain (12).
xOdai ratipua xita-e rokh- $i$ sula $\quad-t u \quad-k \quad$ sa $\quad-i$ thak $-e$ every morning Sita-ERG stop -NF garment-CLF-ACC watch-NF stay -3.SUB 'Every morning Sita stops and gazes at the coat.'
(Data from Keri Edwards, RC:5; gloss adjusted MP)

\subsubsection{TAM}

We also noted that verb serializations cross-linguistically tend to take the same TAM specification. Likewise in Assamese, morphological markers of tense and

\footnotetext{
${ }^{6}$ I use the term "subject" here quite informally to indicate the S/A of an intransitive or transitive verb. A more complete presentation of argument structure in Assamese may be found in Edwards (2004).
} 
aspect are suffixed to the chain-final verb only and have scope over all preceding verbs in the clause; compare examples (13) and (14) with (5) above.

$$
\begin{array}{lllll}
* m O i & \text { likh }-i l & -i & k h a & -u \\
\text { 1.NOM } & \text { write }-\mathrm{PST} & -\mathrm{NF} & \text { eat } & -1 . \mathrm{SUB}
\end{array}
$$

Assamese

? 'I wrote and then I eat.'

$\begin{array}{lll}m O i \quad l i k h-i & k h a & -m \\ \text { 1.NOM write-NF } & \text { eat } & -1 . F U T \\ \text { 'I'll write then eat.' } & & \end{array}$

Assamese

\subsubsection{Polarity}

While the extent to which serialized verbs must fall under the same polarity specification may vary across languages, it is frequently the case that serialized verbs with a grammatical or other modifying function cannot be independently negated; or, if they are, the erstwhile lexical sense is thereby forced to re-emerge to code a distinct event (Post 2003). ${ }^{7}$ Consider the Thai sentence khăw khı̆on paj lécw 's/he write go already,' a so-called "disposal" or "despatch" construction with the rough sense $\sim$ 's/he wrote it away' (i.e. wrote it and thereby dispensed with it) (Enfield To appear; Li and Thompson 1981). A negator morpheme preceding the lexical verb 'write' has scope over the clause, viz. "s/he didn't write it away"; however, in the borderline ungrammatical sentence ?khăw khĭon màj paj lécw, 's/he write not go already,' negation has scope over the erstwhile 'go' verb only, thereby forcing a reading of two disjoined events: "s/he wrote (but) didn't go yet".

Now consider the Assamese examples (15-17): as illustrated in (15), di 'give' in chain-final position indicates "purposeful" or "willful" activity with respect to the chain-initial or medial, semantic main verb. (16) shows that negation of the chain-final (i.e. the grammatically-functioning) verb has scope over all verbs in the clause. ${ }^{8}$ However, negation of the semantic main verb as in (17) has narrow scope. This will force a grammatically-functioning chain-final verb like 'give' to revert to its lexical sense. Thus, while the sites of clause and narrow-scope negation in Thai and Assamese are effectively reversed, the effect of narrowscope negation on the event structure is analogous.

$$
\begin{array}{llll}
m O i \quad \text { por- } i \quad d i & -l & -u \\
\text { 1.NOM fall-NF give-PST } & -1 . \mathrm{SUB} \\
\text { 'I purposefully fell.' }
\end{array}
$$

Assamese

\footnotetext{
${ }^{7}$ Chinese resultative constructions present an important exception to this ( $\mathrm{Li}$ and Thompson 1981).

${ }^{8}$ Both suffixal and prefixal negation occur in Assamese, with no semantic difference in simple perfective clauses.
} 


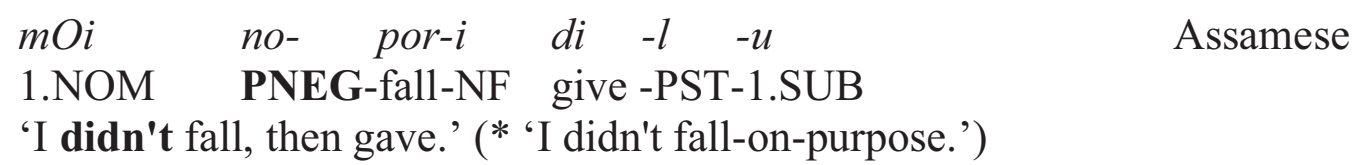

\subsection{Grammaticalization of chain-final verbs}

As discussed in section (4), serial verb constructions have been identified as a primary channel for the recruitment of new functional morphemes in a number of West African and Southeast Asian languages, among others. Assamese has nowhere near the number of grammatically-functioning serial verbs as does e.g. Lahu (Matisoff 1973); those found to date are listed by root in Table 1. ${ }^{9}$

\begin{tabular}{|l|l|l|}
\hline VStem & Meaning as lexeme & Function in chain-final position \\
\hline$a s$ & 'have/exist' & Progressive aspect \\
\hline$t h a k$ & 'stay' & Durative aspect \\
\hline$l o$ & 'take' & Inward-directedness; Diminution \\
\hline$d i$ & 'give' & Outward-directedness; Willfulness; Diminution \\
\hline go & 'go' & Motion away from reference point \\
\hline$a h$ & 'come' & Motion towards reference point \\
\hline$p e l a$ & 'throw' & 'Disposal' perfect \\
\hline$p a$ & 'get' & Achievement \\
\hline$s a$ & 'see' & 'Tentative' \\
\hline
\end{tabular}

Table 1 - Summary of Assamese verb stems with grammatical function in chain-final position

As shown, each may form the single verb of a simplex predicate, but in chainfinal position will aspectually or otherwise modify the chain-medial semantic main verb. Due to space constraints we cannot review their semantics in any great detail, but the following will at least outline what I believe to be their primary functions. As shown in (18), the stem as in a simple predication has the sense 'have/exist', while as a chain-final serial verb, it gives Progressive aspect; interpretation of an event-sequence is impossible (19). Durative aspect is similarly coded by chain-final thak 'stay' (20-21).

$$
\begin{aligned}
& \text { radz as } \quad-e \\
& \text { Raj have/exist }-3 . S U B \\
& \text { 'Raj is here.' }
\end{aligned}
$$

\footnotetext{
${ }^{9}$ For discussion of some affixes in Assamese which appear to have recently developed from serial verbs, see Post (forthcoming).
} 
$(19)$

mOi pela- $i$ as $-u$

1.NOM drop-NF PROG-1.SUB

'I am dropping/tossing.'

* 'I drop and then am here.'

(20) $m O i$ thak $-i l-u$

1.NOM stay -PST -1.SUB

'I stayed.'

(21) $\quad m O i \quad$ likh $-i \quad$ thak $-i l \quad-u$

1.NOM write-NF DUR-PST -1.SUB

'I kept writing.'

?'I wrote and then stayed.'

Chain-final 'take' and 'give' are polyfunctional, according to the semantics of the main verb in probable conjunction with discourse conditions which are not yet well-understood. Respectively, they code Inward and Outward-directness of activity from the referent of the clause subject (22-24). While 'take' can often be interpreted in this sense as a Self-benefactive (for example, 'die-take' is unacceptable), 'give' is only rarely and in transparent cases interpretable as a Benefactive (23). Rather, the typical interpretation is 'Willfulness; Purposefulness' of activity, independent of an affected second or third argument (so, for example, 'see-take' gives the sense 'look despite not being supposed to'). Both 'take' and 'give' can also be employed in Diminution, as in English and many other languages (25-26).

(22) radz-e siti $-k h O n$ porh $-i$ lo $-l \quad r r$ Raj -ERG letter -CLF read-NF take-PST -3.SUB

'Raj read the letter (to himself, NOT to someone else).'

$\begin{array}{llllll}m O i \quad x O h a i & k o r & -i & d i & -l & -u \\ \text { 1.NOM help } & \text { do } & -\mathrm{NF} & \text { give } & \text {-PST } & -1 . \mathrm{SUB} \\ \text { 'I helped.' } & & & & & \end{array}$

(24) ta-i sula -tu dzol-a $-i \quad d i \quad-l \quad-e$

3 -F garment-CLF burn-CAUS-NF give-PST-3.SUB

'She burned the coat (despite her reluctance).'

(Data from Keri Edwards, RC:27; adjusted MP)

(25) $m O i$ thak-i lo $-l \quad-u$

1.NOM stay-NF take-PST-1.SUB

'I stayed/I took a rest.' 


$$
\begin{aligned}
& m O i \quad g O l p O \quad k o-i \quad d i-l \quad-u \\
& \text { 1.NOM story say -NF give-PST-1.SUB } \\
& \text { 'I spun a yarn / told a little story.' }
\end{aligned}
$$

More research into the semantics and discourse functions of serialized 'give' and 'take' is clearly warranted.

Chain-final go 'go' and $a h$ 'come' code Directedness Away from or Towards a reference point in motion predicates. Parallels are found in Thai, Chinese, and numerous other serializing languages (27-28).

$$
\begin{array}{llll}
m O i \quad \text { dukan-olOi } \quad \text { dor }-i & \text { go-l } & -u \\
\text { 1.NOM store -ALL run -NF } & \text { go-PST } & -1 . \mathrm{SUB} \\
\text { 'I ran (away from initial position) } & \text { to the store.' }
\end{array}
$$

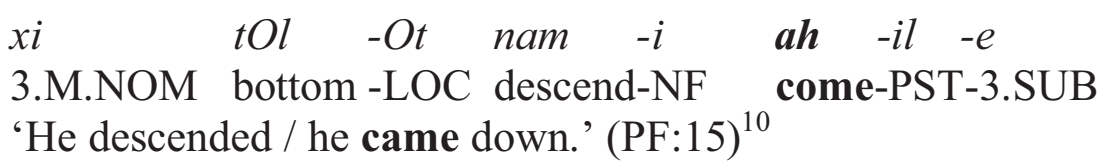

Chain-final $p a$ 'get' and pela 'throw' are frequent in texts in their capacity as markers of the partially overlapping functions 'Achievement/Completion' and 'Disposal Perfect' respectively (29-30, also 7 above).

$$
\text { xi gOs-Or dal }-t u \text {-t khund-a kha-i pa-l }-e
$$

3.M.NOM tree-GEN branch-CLF-LOC pound-NZR eat -NF get-PST-3.SUB 'He collided with a tree branch.' (lit. 'he got a pound-taking on a tree branch') (Data from Joana Jansen BDF: 12; adjusted MP)

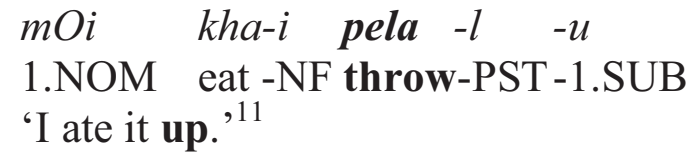

Finally, chain-final $s a$ 'see' gives what Matisoff (1973) has described as 'Tentative' aspect. Similar to English ' $x$ and see', it is used when an actor performs an action cautiously or with a view toward evaluating the result (31); note that an event-sequence is not denoted, since the event denoted by the medial verb is in fact not carried to completion.

$$
\begin{array}{llll}
x i & \boldsymbol{k} \boldsymbol{h} \boldsymbol{a}-i & \boldsymbol{s} \boldsymbol{a}-\boldsymbol{l} & -e \\
\text { 3.M.NOM eat }-\mathrm{NF} & \text { see-PST-3.SUB } \\
\text { 'He tasted it." } & &
\end{array}
$$

\footnotetext{
${ }^{10} \mathrm{cf}$. Chinese tā xià lái le 's/he descend come PFV' $\rightarrow$ 's/he descended (toward reference point)'

${ }^{11}$ Compare the Thai examples in section 4.1.3 above.

${ }^{12}$ cf. Lahu $q \hat{o} ~ n i$ 'hoe and see (how it goes)' < $n i$ 'see' (Matisoff 1991: 409), also Japanese tabete $m i-y_{0}$ 'Why don't (we/you/I) have a taste.' $<m i$ 'see'
} 
It is certainly possible that further research will uncover both more serial verbs in Assamese as well as other functions for the verbs identified here.

\section{Conclusion}

I have endeavored in this paper to present a view of serial verb constructions as a typologically common formal structure whose salient properties are explainable in terms of their origin as integrated clause chains. I then tried to show that the erstwhile conjunctive participial construction in Assamese is analyzable in the modern language as a serial verb construction, both in terms of its synchronic properties and its evident diachronic origin. However, following the review of serial verbs and their functions found to date (section 4.2), it should be clear that there are nowhere near as many of either as there are in many Southeast Asian languages, and we might well wonder why.

While a full answer to this question lies outside the scope of this paper, it will surely include facts concerning the typological profile of Assamese. As has been seen, a handful of morphological markers of tense and aspect remain to modern Assamese, often giving speakers alternatives between morphological and periphrastic expressions - this is usually not the case in the more isolating languages of Southeast Asia. Furthermore, although we cannot treat the subject in any detail here, we may note that other subordination strategies exist to code predicatemodifying expressions in Assamese which are functionally distinct from its serial verb constructions, but which are probably coded by serializations in other languages. Research into other types of adverbial subordination in Assamese and their discourse functions is very much needed indeed. ${ }^{13}$

Finally, there remains a question of language contact as a possible motivating factor for the rise of verb serialization (among other things) in Assamese. Whether or not contact should be supposed to account for what is in fact a typologically common development across languages remains to be seen; ${ }^{14}$ however, until a more detailed analysis of the behavior and discourse distribution of multi-verb constructions in South Asian languages appears, our approach to this question will appear somewhat one-sided. In any case, I hold out hope that the present study will represent a step in that direction.

\footnotetext{
${ }^{13}$ Again, a good beginning is provided by Bisang (1995). However, it is not yet entirely clear where a language with both subordinating and serializing strategies would fit into his typology. As more languages from the South/Southeast Asian frontiers are described in detail, we may find a clearer picture will emerge.

${ }^{14}$ While the existence of serial verbs in Indic languages might be attributable to a Dravidian substrate (Tamil, cf. Steever 1989), it is less clear why Assamese in particular should retain this trait to such a degree that typological and/or contact factors should not (perhaps additionally) be taken into account.
} 


\section{Abbreviations}

$1 \quad$ First person

3 Third person

ALL Allative case marker

ACC Accusative case marker

CLF Classifier

CONJ Conjunctive coordinator

ERG Ergative case marker

GEN Genitive case marker

INST Instrumental case marker

LOC Locative case marker

M Masculine gender marker
NF Non-finite marker

NOM Nominative case marker

NZR Nominalizer

PF Perfect aspect marker

PFV Perfective aspect marker

PNEG Prefixal negator

PST Past tense marker

SG Singular number marker

SNEG Suffixal negator

SUB Subject agreement marker

TOP Topic marker

\section{References}

Benom, C. 2003. Classifiers in Assamese: A preliminary report. Ms., University of Oregon.

Bhattacharjya, D. 2001. The Genesis and Development of Nagamese: Its Social History and Linguistic Structure. Ph.D. diss., City University of New York.

Bisang, W. 1995. Verb serialization and converbs - differences and similarities. In M. Haspelmath and E. König (eds.) Converbs in Cross-Linguistic Perspective: Structure and Meaning of Adverbial Verb Forms - Adverbial Participles, Gerunds, 137-88. Berlin: Walter de Gruyter.

Brown, P. J. 1997. Explicator compound verbs in Kannada. Ph.D. diss., La Trobe University, Bundoora, Australia.

Burton-Page, J. 1957. Compound and conjunct verbs in Hindi. Bulletin of the School of Oriental and African Studies 19: 469-78.

Byrne, F. 1990. 'Tense', scope and spreading in serial verb constructions. In When Verbs Collide: Papers from the 1990 Ohio State Mini-Conference on Serial Verbs, 149-77. Columbus, OH: Ohio State University.

DeLancey, S. 1991. The origins of verb serialization in Modern Tibetan. Studies in Language 15(1): 1-23.

Edwards, K. 2004. Agency, Individuation, and Affectedness: Basic Clause Structure in Assamese with Special Attention to Grammatical Relations and their Semantic Correlates. MA Thesis, University of Oregon.

Enfield, N. J. To appear. Verbs and multi-verb constructions in Lao. In A. Diller and J. A. Edmondson (eds.) Tai-Kadai Languages. London: Routledge-Curzon.

Givón, T. 1975. Serial verbs and syntactic change: Niger-Congo. In C. N. Li (ed.) Word Order and Word Order Change, 49-112. Austin: Texas University Press. 
Givón, T. 1991. Serial verbs and the mental reality of 'event': Grammatical vs. cognitive packaging. In E. C. Traugott and B. Heine (eds.) Approaches to Grammaticalization, I: Focus on Theoretical and Methodological Issues, 81127. Amsterdam: John Benjamins.

Givón, T. 1995. Functionalism and Grammar. Amsterdam: John Benjamins.

Goswami, G., and J. Tamuli. 2003. Assamese. In G. Cardona and D. Jain (eds.) The Indo-Aryan Languages, 391-443. London/New York: Routledge.

Haas, M. 1964. Thai-English Student's Dictionary. Stanford: Stanford University Press.

Hacker, P. 1961. On the problem of a method for treating the compound and conjunct verbs in Hindi. Bulletin of the School of Oriental and African Studies 24: 484-516.

Hook, P. E. 1974. The Compound Verb in Hindi. Ann Arbor: University of Michigan Center for South and Southeast Asian Studies.

Kachru, Y. 1979. Pragmatics and verb serialization in Hindi-Urdu. Studies in the Linguistic Sciences 9(2): 157-69.

Kachru, Y. 1993. Verb serialization in syntax, typology and historical change. In M. K. Verma (ed.) Complex Predicates in South Asian Languages. New Delhi: Manohar.

Kachru, Y., and R. Pandharipande. 1980. Toward a typology of compound verbs in South Asian languages. Studies in the Linguistic Sciences 10(1): 113-24.

Kakati, B. 1995. Assamese, its Formation and Development: A Scientific Treatise on the History and Philology of the Assamese Language. Gauhati, Assam, India: LBS.

Li, C. N., and S. A. Thompson. 1973. Serial verb construction in Mandarin Chinese: Subordination or coordination? Proceedings of the 9th Annual Meeting of the Chicago Linguistic Society ("You take the high node and I'll take the low node"), 96-103. Chicago: Chicago Linguistic Society.

Li, C. N., and S. A. Thompson. 1974. Historical change of word-order: A case study in Chinese and its implications. In J. Anderson and C. Jones (eds.) Historical Linguistics A. Amsterdam: North Holland Publishing Company.

Li, C. N., and S. A. Thompson. 1981. Mandarin Chinese: A Functional Grammar. Berkeley: University of California Press.

Lord, C. 1993. Historical Change in Serial Verb Constructions. Amsterdam: John Benjamins.

Matisoff, J. A. 1969. Verb concatenation in Lahu: The syntax and semantics of 'simple' juxtaposition. Acta Linguistica Hafniensia 12: 69-120.

Matisoff, J. A. 1973. The Grammar of Lahu. Berkeley: University of California Press.

Matisoff, J. A. 1991. Areal and universal dimensions of grammatization in Lahu. In E. C. Traugott and B. Heine (eds.) Approaches to Grammaticalization, I: Focus on Theoretical and Methodological Issues, 383-453. Amsterdam: John Benjamins. 
Nespital, H. 1989. Verbal aspect and lexical semantics in Indo-Aryan languages: The typology of verbal expressions ('compound verbs') and their relation to simple verbs. Studien zur Indologie und Iranistik 15: 159-96.

Pandharipande, R. 1993. Serial verb construction in Marathi. In M. K. Verma (ed.) Complex Predicates in South Asian Languages, 177-95. New Delhi: Manohar.

Post, M. 2003. Grammaticalization and Lexical Replacement: A Comparative Study on Thai and Chinese. MA Thesis, University of Oregon, Eugene.

Post, M. Forthcoming. Grammaticalization and the discourse distribution of serial verbs in Assamese. In Proceedings of the 14th Annual Meeting of the Southeast Asian Linguistics Society, May 19-24 2004, Thammasat University, Bangkok, Thailand.

Schiller, E. 1990. On the definition and distribution of serial verb constructions. In When Verbs Collide: Papers from the 1990 Ohio State Mini-Conference on Serial Verbs. Columbus, OH: Ohio State University.

Sebba, M. 1987. The Syntax of Serial Verbs. Amsterdam: John Benjamins.

Seuren, P. A. M. 1990. Serial verb constructions. In When Verbs Collide: Papers from the 1990 Ohio State Mini-Conference on Serial Verbs, 14-33. Columbus, $\mathrm{OH}$ : Ohio State University.

Steever, S. B. 1989. The Serial Verb Formation in Dravidian Languages. Delhi: Motilal Barnasidass.

Sun, C.-F., and T. Givón. 1985. On the so-called SOV word order in Mandarin Chinese: A quantified text study and its implications. Language 61(2): 329-51.

Research Centre for Linguistic Typology

La Trobe University

Bundoora, VIC 3086, Australia

m.post@latrobe.edu.au 